\title{
Linking Transport and Land Use Planning: The Microscopic Dynamic Simulation Model ILUMASS
}

\author{
D. Strauch ${ }^{1}$, R. Moeckel ${ }^{2}$, M. Wegener ${ }^{3}$, J. Gräfe ${ }^{4}$, H. Mühlhans ${ }^{5}$, G. \\ Rindsfüser $^{6}$ \& K.-J. Beckmann ${ }^{7}$
}

${ }^{1}$ German Aerospace Center (DLR), Institute of Transport Research

Rutherfordstr. 2, 12489 Berlin, Germany

Telephone: +49 (0) 30 67055234, FAX: +49 (0) 3067055202

Email: dirk.strauch@dlr.de

${ }^{2}$ Institute of Spatial Planning (IRPUD), University of Dortmund

August-Schmidt-Str. 6, 44221 Dortmund, Germany

Telephone: +49 (0) 231 7552127, FAX: +49 (0) 2317554788

Email: rm@irpud.rp.uni-dortmund.de

${ }^{3}$ Spiekermann \& Wegener (S\&W) Urban and Regional Research

Lindemannstr. 10, 44137 Dortmund, Germany

Telephone: +49 (0) 231 1899441, FAX: +49 (0) 2311899443

Email:mw@spiekermann-wegener.de

${ }^{4}$ Center for Applied Informatics (ZAIK), University of Cologne

Weyertal 80, 50923 Cologne, Germany

Telephone: +49 (0) 221 4706010, FAX: +49 (0) 2214705160

Email: graefe@zpr.uni-koeln.de

\footnotetext{
5,6,7 Institute for Urban and Transport Planning, RWTH Aachen University Mies-van-der-Rohe-Str. 1, 52074 Aachen, Germany, FAX: +49 (0) 2418022247

5Telephone: +49 (0) 241 8025203; Email: muehlhans@isb.rwth-aachen.de

${ }^{6}$ Telephone: +49 (0) 241 8026204; Email: rindsfueser@isb.rwth-aachen.de

7Telephone: +49 (0) 241 8025200, Email: kj.beckmann@isb.rwth-aachen.de
}

\begin{abstract}
The project ILUMASS (Integrated Land-Use Modelling and Transportation System Simulation) aims at embedding a microscopic dynamic simulation model of urban traffic flows into a comprehensive model system incorporating changes of land use, the resulting changes in transport demand, and the impacts of transport on the environment. Microsimulation modules include models of demographic development, household formation, firm lifecycles, residential and non-residential construction, labour mobility on the regional labour market and household mobility on the regional housing market. These modules will be closely linked with the models of daily activity patterns and travel and goods movements modelled in the transport parts of ILUMASS. The acquisition of data of daily activity patterns are described in a new approach. The goal was to utilize a computerized hand-held survey instrument that allows the gathering of information from subjects at regular intervals as close in time to real decision
\end{abstract}


points. The computerized platform, a handheld personal digital assistant (PDA), also enables the instrument to automatically trace and/or prompt for certain attributes of the decisions process. The ILUMASS project aims at integrating modules to a complete modelling system. In the ILUMASS model system there are both uni-dimensional cause-effect relationships as well as strongly linked connections between the activity reports of the surveyed individuals, the daily schedules, and the trip times in the network that are calculated by different submodules. Consistency between the data set thus necessitates consideration of the interactions between the modules. The solution of this problem therefore requires an iterative approach.

\section{Introduction}

All cities in Europe struggle with the problems of urban sprawl and traffic congestion, yet mostly with little success. There is a growing awareness that market forces will continue to lead to ever more dispersed, energy-wasteful urban settlement patterns and that only a combination of land-use policies, such as the promotion of higher-density, mixed-use urban forms, and of transport policies to promote public transport and contain the automobile can free metropolitan areas from their increasing auto-dependency. It is therefore necessary to develop modelling approaches in which the two-way interaction between transport and land use is modelled (Alvanides et al., 2001).

Today there is a new interest in integrated models of urban land use and transport provoked by the environmental debate. In the United States and in Europe the number of integrated urban land-use transport models that can be used for assessing environmental impacts of land-use and transport policies is increasing (Wegener, 1998).

\section{Overview of the joint research project ILUMASS}

The project ILUMASS (Integrated Land-Use Modelling and Transportation System Simulation) is part in the development stated above.

ILUMASS aims at embedding a microscopic dynamic simulation model of urban traffic flows into a comprehensive model system that incorporates changes of land use, the resulting changes in activity behaviour and in transport demand, and the impacts of transport on the environment (Figure 1, see also Strauch et al., 2002; Wegener, 1998). The results of the policy scenarios will contribute to the knowledge about feasible and successful policies and policy packages to achieve sustainable urban transport (Claramunt et al., 2000).

The ILUMASS project aims at developing, testing, and applying a new type of integrated urban land-use/transport/environment (LTE) planning model. Urban LTE models simulate the interaction between urban land-use development, transport, demand, traffic and environment (Figure 1). 


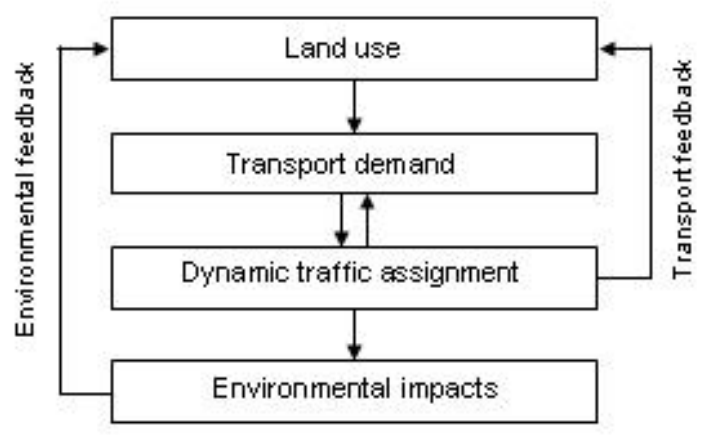

Figure 1. Feedbacks in LTE models (Design: IRPUD Dortmund).

The distribution of land uses in the urban region, such as residences, workplaces, shops and leisure facilities, creates demand for spatial interaction, such as work, shopping or leisure trips. These trips occur as road, rail, bicycle or walking trips over the transport network in the region, and they have environmental impacts. There are two important kinds of feedback: The accessibility provided to locations in the region by the transport system influences the location decisions of developers, firms and households. Firms and households also take environmental factors, such as clean air and absence of traffic noise, in location decisions into account.

\subsection{Project organisation and main objectives of ILUMASS}

ILUMASS is conducted by a consortium of German research institutions consisting of the German Aerospace Center (DLR) in Berlin, the Institute of Spatial Planning of the University of Dortmund (IRPUD) together with Spiekermann \& Wegener Urban and Regional Research (S\&W), the Institute of Urban and Transport Planning of the University of Aachen (ISB), the Institute of Theoretical Psychology of the University of Bamberg (IfTP), the Centre of Applied Computer Science of the University of Cologne (ZAIK) and the Institute of Sustainable Infrastructure Planning of the University of Wuppertal (LUIS) under the co-ordination of DLR.

The work programme of ILUMASS consists of six interrelated work packages:

- Microsimulation of changes in land use (IRPUD/S\&W).

- Microsimulation of activity patterns and travel demand (ISB/IfTP).

- Microsimulation of traffic flows by dynamic traffic assignment (ZAIK).

- Simulation of goods transport (DLR).

- Microsimulation of environmental impacts of transport and land use (LUIS).

- Integration and co-ordination (DLR).

The main components of ILUMASS are shown in Figure 2: 


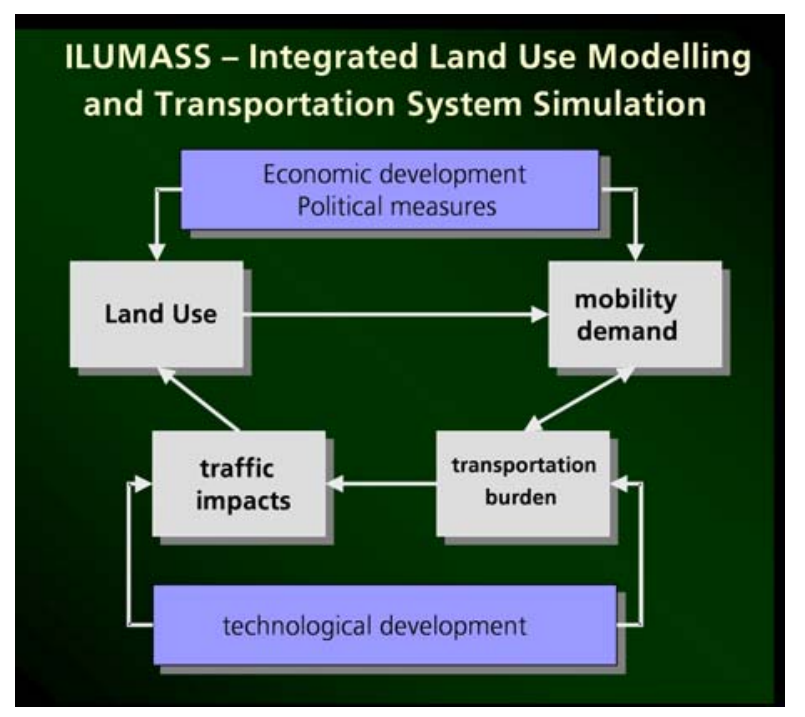

Figure 2. Main components of ILUMASS.

The land-use component of ILUMASS is based on the land-use parts of the existing urban simulation model developed at the Institute of Spatial Planning of the University of Dortmund (IRPUD) but is microscopic like the transport parts of ILUMASS. Microsimulation modules include models of demographic development, household formation, firm lifecycles, residential and non-residential construction, labour mobility in the regional labour market and household mobility in the regional housing market. The Microsimulation of changes in land-use is described in detail in chapter 4.1.

The transport part of ILUMASS models daily activity patterns and travel and goods movements based on state-of-the-art models of household activity patterns and the resulting mobility behaviour of individual household members and on a microscopic simulation model of travel flows developed by a team of German universities in earlier projects. The Microsimulation of activity pattern and travel demands is described in detail in chapter 4.2.

The environment modules of ILUMASS calculate the environmental impacts of transport and land use modelled, such as greenhouse gas emissions, air pollution, traffic noise, barrier effects and visual impairment of transport and selected emissions of land uses.

The ILUMASS approach takes account of deficiencies of existing urban land-use/transport planning models which are too aggregate in their spatial, temporal and substantive resolution to model aspects that are crucial for achieving sustainable urban transport, such as

- multipurpose unimodal and intermodal trip chains and time of day of trips,

- the interaction between activity and mobility patterns of household members,

- new lifestyles and work patterns, such as part-time work, telework and teleshopping,

- the interaction between travel demand, car ownership and residential and firm location,

- the interaction between land use and built form and mobility behaviour,

- environmental impacts of transport such as traffic noise and exposure to air pollution,

- feedback from environmental impacts to the behaviour of firms and households.

\subsection{The microscopic approach in ILUMASS}


The innovation of this approach is a continuous microscopic transformation of land use, activity and transport demand, and environmental impacts. First, a synthetic population is generated (Moeckel, Spiekermann and Wegener, 2003). The design of the land-use model takes into account that the collection of individual micro data (i.e. data which because of their micro location can be associated with individual buildings or small groups of buildings) or the retrieval of individual micro data from administrative registers for planning purposes is neither possible nor, for privacy reasons, desirable. The land-use model therefore works with synthetic micro data, which can be retrieved from generally accessible public data. The synthetic population consists of households and persons that make activities, firms that provide workplaces and that offer goods or services, and buildings for residential, commercial, or public use. Since the synthetic micro data are statistically equivalent to real data a microsimulation model can run with synthetic data.

The activity generation model, which replicates and forecasts time dependent O-D-matrices (input for the traffic flow model), is based on the microsimulation of the individual activity scheduling process. For each simulated person - one person stands for a defined number of people of the synthetic population - the daily/weekly sequence of different activities and trips is generated. In a first step for each person an individual activity repertoire is generated, which contains a set of activities and their characteristic attributes for execution e.g. duration, frequencies, priorities and period of time (preferred start/end time) including an individual set of possible locations. In a second step, based on a skeleton schedule (routine or habitual activities), the different activities of the repertoire are put together in an individual activity programme. The modelling of this activity scheduling process underlies a lot of decisions (long-, mid- and short-term), about which activity has to be scheduled next, how to perform the activity, and how to solve conflicts which may occur between different activities and trips during the scheduling process. Therefore an empirical database is build up, which contains initial information on different activity attributes on time, space and mode as well as parameters describing the planning related attributes such as flexibility, variability and routines. The activity generation model is integrated in an iterative modelling process and linked with information about accessibility of locations and travel times and therefore it is directly connected to the land-use and traffic flow simulation (Schäfer et al., 2001; Thill, 2000). The microscopic traffic flow model establishes the connection between the infrastructure of the city and the individual activity behaviour. In that step of the model, the planned trips are realized taking their interaction into account. As a result information about the practicability of the planned trips are available. That information is used in an iteration process in which plans are rescheduled leading to an equilibrium situation in which all plans are feasible. In addition to this short-term feedback you get the environmental impact of the traffic which can be used to influence long-term plannings of the simulated individuals.

The result is a comprehensive model system incorporating changes of land use, the resulting changes in activities and in transport demand, and the impacts of transport on the environment.

\section{Study Area}

The study region for tests and first applications of the model is the urban region of Dortmund (Figure 3). The area consists of the city of Dortmund and its 25 surrounding municipalities with a population of about 2.6 million. The area is subdivided into 246 statistical zones. However, the spatial resolution of 246 zones is not sufficient for microsimulation of transport and land use and for modelling environmental impacts such as air quality and traffic noise. These types of models require a much higher spatial resolution. Therefore, raster cells of 100 
by $100 \mathrm{~m}$ in size are introduced in the modelling system and are used as addresses for activities. In order to bridge the data gap between zones and raster cells, GIS-based techniques are used to disaggregate zonal data to raster cells. Figure 4 is a detailed map of the city centre of Dortmund (the small square in the centre of Figure 3) showing the built-up area, the zone boundaries and the raster cells. In total, about 207,000 raster cells cover the study area.

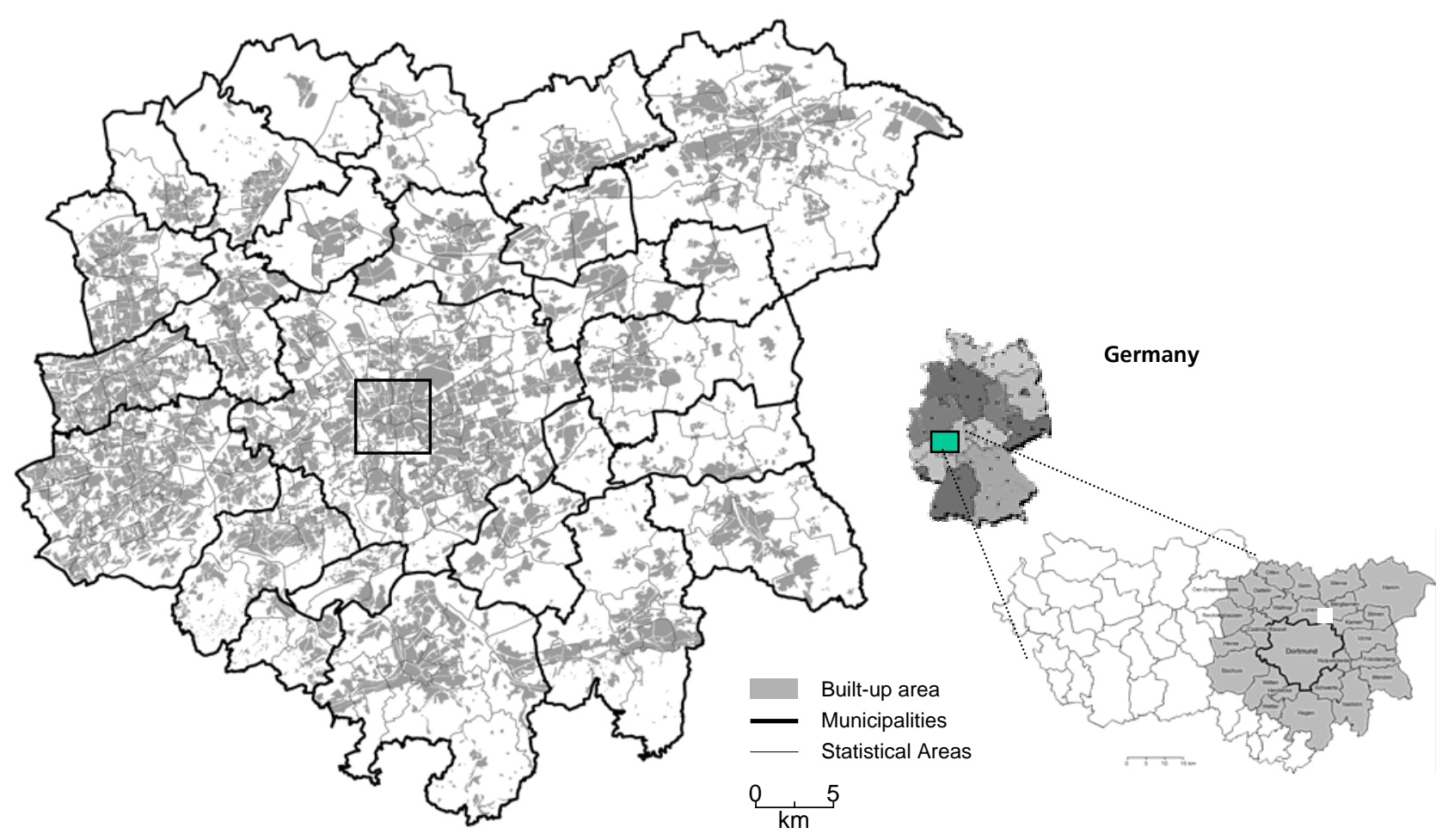

Figure 3. The study region of Dortmund and its 25 surrounding communities (Source: IRPUD Dortmund, supplemented).
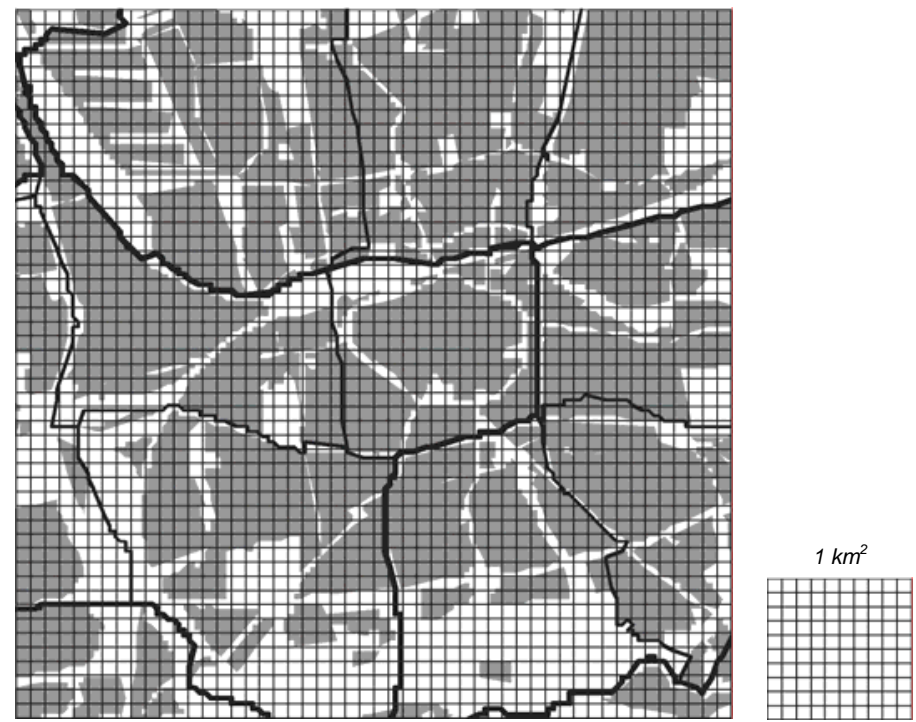

Figure 4. The Dortmund city centre with raster cells (Source: IRPUD Dortmund). 


\section{Microsimulation modules in ILUMASS}

\subsection{Microsimulation of changes in land-use}

The module Microsimulation of changes in land-use is developed by the Institute of Spatial Planning of the University of Dortmund (IRPUD) and the partner Spiekermann \& Wegener (S\&W), Urban and Regional Research, Dortmund.

Major input data are synthetic 'populations' of individual housing, households, industrial and commercial buildings, firms and vehicles in the base year as well as the road and public transport networks. Households and household members, firms and workers, cars and commercial vehicles and residential and non-residential buildings are aged by one simulation period and undergo changes by choices, transitions or policies occurring during the simulation period. For each forecasting year, the distributions of households, persons, firms and workers are passed to the microsimulation modules forecasting travel and freight transport demand and dynamic traffic assignment. The traffic flows, link loads and travel times and costs so generated are fed back to the land use model in which they, through accessibility, affect the behaviour of developers, households and firms (transport feedback).

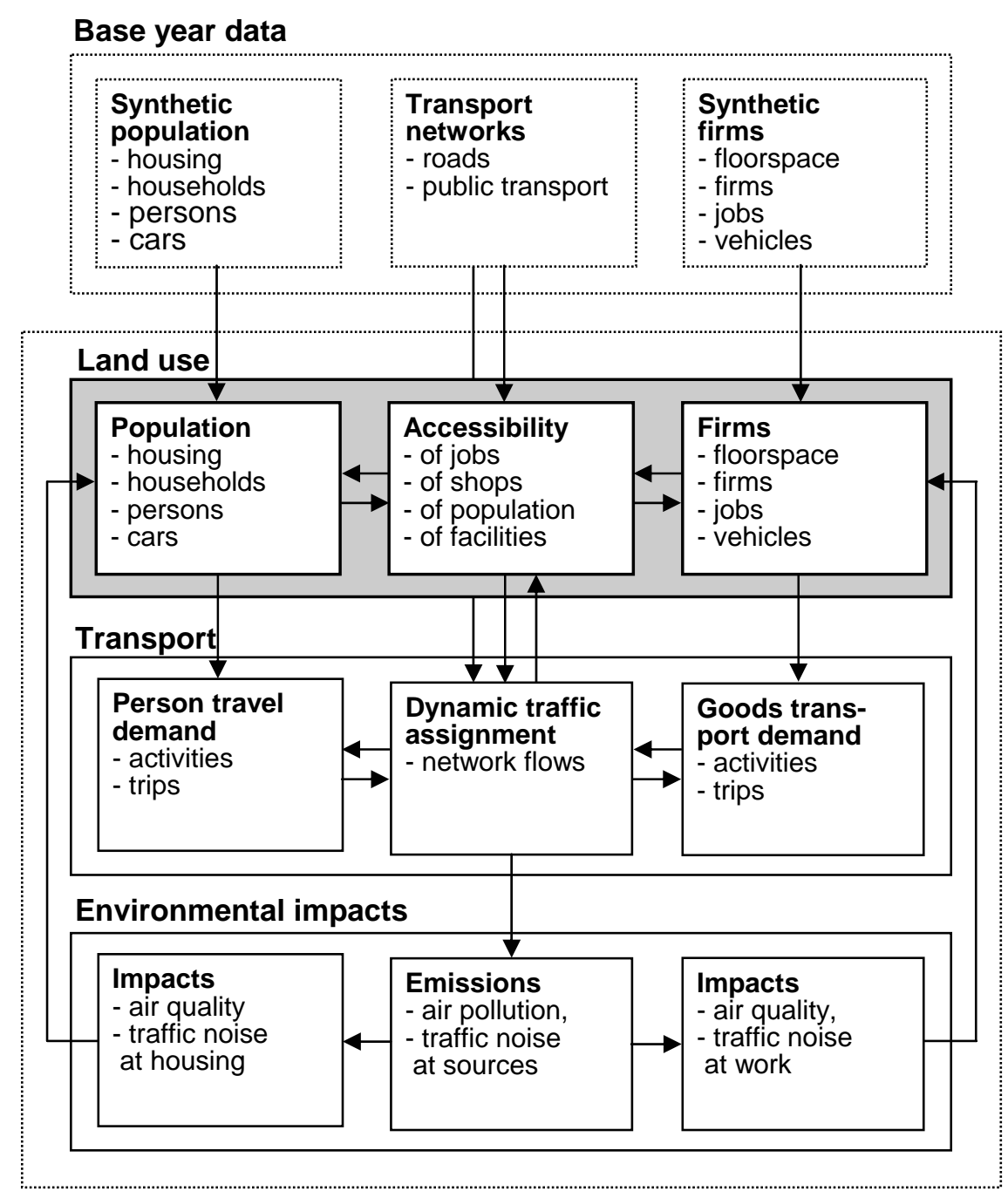

ILUMASS model

Figure 5. The ILUMASS model and the Integration of the land-use model (Design: M. Wegener). 
In addition they serve as input to the environmental modules which calculate the resulting environmental impacts of transport and land use. These, in turn are fed back to the land use models and affect the location decisions of developers, households and firms (environmental feedback) (Figure 5). Work on the synthetic population of households is ongoing (Moeckel, Spiekermann and Wegener, 2003). Population, household, labour, employment and housing data were collected for the 246 zones of the study region and disaggregated to raster cells of $100 \times 100$ m size using GIS-based land-use data as ancillary information (Spiekermann and Wegener, 2000). In addition, data on schools, universities, car ownership, land prices, household income and parking facilities were collected and disaggregated to raster cells using kriging and other spatial interpolation methods. The road and public transport networks of the study region were updated. Work has begun on the dynamic ageing of population, households and housing submodels.

The integrated model will be calibrated using data from household activity and travel surveys conducted in the study region and validated using aggregate time series data of population, housing and employment as well as data from traffic counts in the study region. The model will then be used to study the likely impacts of various policy alternatives in the fields of land use and transport planning. Scenarios might cover land use planning alternatives, such as policies promoting high-density mixed-use inner-city development or policies fostering decentralised polycentric regional development, or transport infrastructure changes, such as new motorways or rail lines, or regulatory policies, such as area-wide speed limits, or monetary policies, such as road pricing, higher petrol taxes, or changes in rail fares or parking fees.

The definition of policy scenarios together with local planners will be a test of the policy relevance of the models. The results of the policy scenarios will contribute to the knowledge about feasible and successful policies and policy packages to achieve sustainable urban transport and may be used for finalising the new land-use plan and mobility master plan of the city of Dortmund.

\subsection{Microsimulation of activity pattern and travel demands}

This module is developed by the Institute for Urban and Transport Planning - RWTH Aachen University.

The main objective therefore is to improve the empirical basis of a scheduling approach integrated in a microsimulation framework of individual behaviour. In ILUMASS this new approach to tracing these underlying activity scheduling decision processes is developed. The goal was to utilize a computerized hand-held survey instrument that allows the gathering of information from subjects at regular intervals as close in time to real decision points. The computerized platform also enables the instrument to automatically trace and/or prompt for certain attributes of the decisions process, such as the sequence of decision inputs, thereby reducing respondent burden.

The project's main interest focussed on the scheduling behaviour of individuals related to out of home activities (and derived travel), especially the sequences of the planning of distinct activity and travel attributes. The latter implying a desire to trace how the timing, location, involved persons, mode etc. attributes of activities is differentially planned. Given this focus, a self-administered and computer-based instrument was considered to have the best chance of capturing the various variables of interest. The successful applications of CHASE (Computerized Household Activity Scheduling Elicitor) and the experiences with a CHASE survey done in Aachen, Germany, in 1999 (Mühlhans and Rindsfüser, 2000) support that 
view. CHASE was the first computer aided self interview of activity scheduling behaviour as it occurred in reality in the household. CHASE was developed by Doherty and Miller (Doherty and Miller, 2000).

The EX-ACT survey was developed with these concerns in mind, and represented a unique solution to the problem. It builds upon these experiences in several key ways:

- Usage of hand-held computers or PDA's (Personal Digital Assistants) instead of laptop computers as in CHASE. This is a major improvement in terms of the flexibility of the interviewees and a situational data entry.

- More in-depth tracking of activity scheduling decisions, including the tracking of entering, modifying or deletion of activities and travel (as with CHASE), but also tracking of how distinct attributes of activities (timing, location, involved persons, mode) are differentially planned. This represents a significant increase in detail, and conceptually is more behaviourally realistic as people often plan different attributes of activities on different time/space horizons.

- Other general improvements in instrument design, concerning forms layout, instrument structure, user friendliness, and preliminary database setup.

The EX-ACT survey was completely administered on the PDA, and included the following main components:

1. pre-interview,

2. exploration of an individuals activity-repertoire,

3. an initial data-entry (already planned activities for the following survey period),

4. a multi-day main scheduling exercise,

5. and a post-interview.

In combination, these various instrument components captured the following information

- Socio-demographic characteristics of the household and the household members.

- Details of available and used transport modes (e.g. car fleet, season tickets owned).

- Interviewees activity-repertoire, assessed through a series of questions concerning the types of activities they typically perform along with their attributes (such as normal frequency, durations).

- One-week continuous activity planning decisions.

- Two days worth of in-depth planning characteristics.

- Resulting/realized activity-travel patterns (as in a traditional diary).

Figure 6 shows the survey cycle and different survey parts. The goal was to gather information about a variety of activities, including typical (routine or habitual), planned and spontaneous activities. Following this, an initial data-entry period is spent describing activities already planned for the week to follow. At this stage, one or more of the attributes of a planned activity can be left undecided (e.g. "haven't thought about the location yet"), or only partially planned (e.g. the planned day might be Monday or Tuesday). The preinterview, the activity-repertoire and the initial data-entry are all completed with the assistance of an interviewer (see also more detailed sections below). During the week to follow, subjects are instructed to continue adding activities (one-week diary) they have planned for future days (using same format as initial data-entry), but also to make modifications/deletions to activities as they change, and update undecided or partially planned activity attributes. They are instructed to do so whenever a decision about one or more activity-attributes or activities as a whole occurs. 


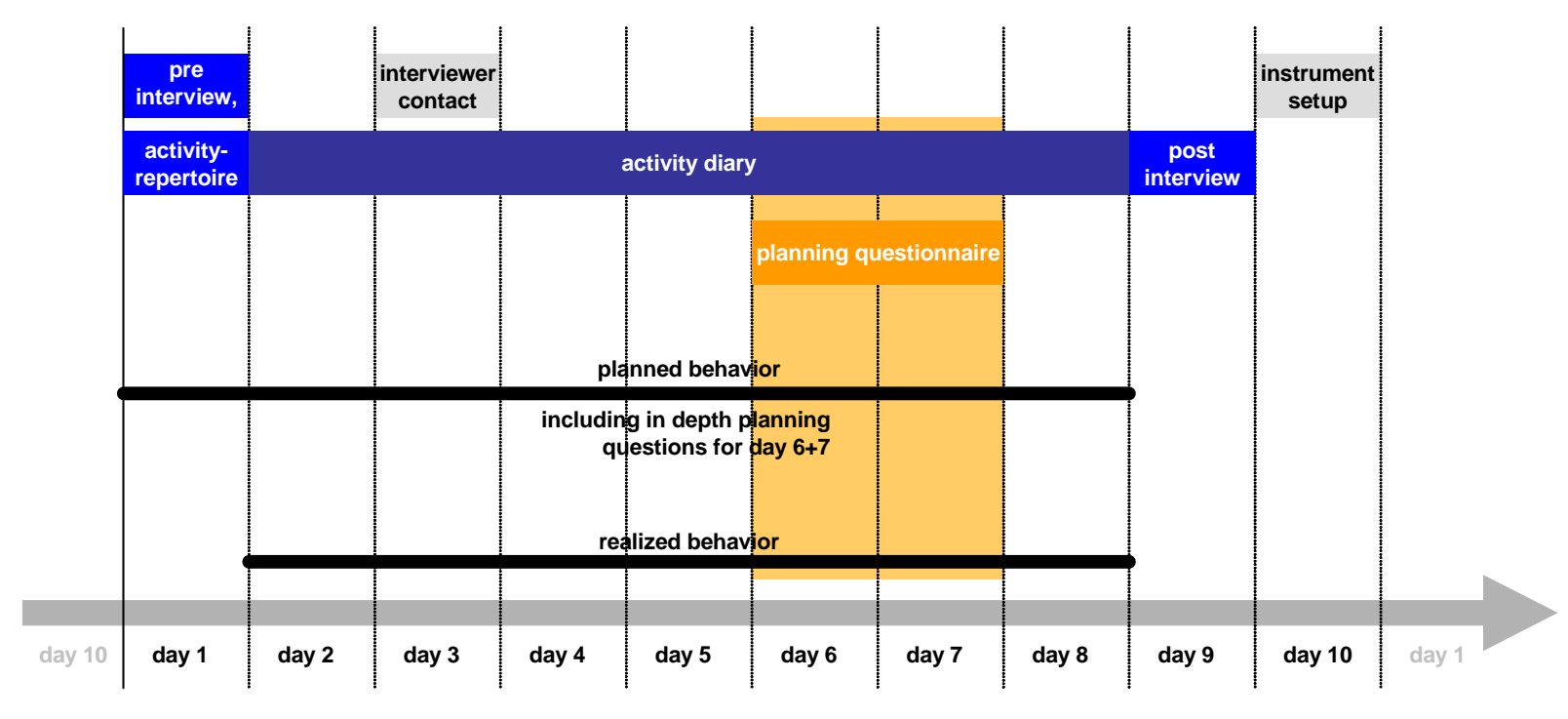

Figure 6. Cycle and parts of the EX-ACT survey (Design: G. Rindsfüser).

All the while, the program automatically tracks the sequence of decisions made, and prompts the user for supplemental information on certain decisions, such as the reasons for the modifications, or when exactly that a particular decision may have been made (this is especially important for tracking impulsive decisions that are entered into the program afterthe-realisation). To reduce respondent burden, these supplemental prompts are asked only for a sample of decisions, weighted more heavily towards the end of the survey (since this allows several days in advance to capture scheduling decisions as they evolve). The final component of the survey is an interviewer assisted post-interview, in which additional information on activities may be asked along with an assessment questionnaire concerning the software and hardware usability.

Although the initial application will result in the equivalent of a week long activity planning diary plus the tracing of the scheduling decisions, the software has been developed with special settings that allow the researcher to pare down the software so that it may serve as an activity or trip diary alone, or be used for a varying number of days. In addition there are many other settings (including a switch between German and English text version), controlled via a database, which allow specific adjustments in the frequency of supplemental prompts and language settings.

Application of the survey on 402 individuals took place from November 2002 to February 2003 in the study area of ILUMASS, the city of Dortmund (see Chapter 3).

The instrument was implemented on a COMPAQ iPaq 3850 (PDA) with Windows CE 3.0 operating system and programmed using Microsoft Visual Embedded Tools in Visual Basic. The software automatically starts upon turning on the PDA. The software was coded by Interactive Instruments (Bonn, Germany) and the survey data collection was conducted by SOKO-Institut (Bielefeld, Germany).

The data interpretation and the database provided through EX-ACT has just started and is still ongoing. So a conclusion can only be tentative. In general the survey was very successful in terms of handling the devices and handling the instrument EX-ACT. Here it 
must be stated that the briefly overview which is described above support a first success of the concept. There are many questions arising while getting deeper insight to the data. These analyses are subjects of the current work. First results of EX-ACT were published in Rindsfüser et al., (2003, in press).

\subsection{Further Microsimulation sub-modules in ILUMASS}

There are further sub-modules in ILUMASS in progress, they will be specified below.

The module Microsimulation of traffic flows is developed by the Centre of Applied Informatics (ZAIK) of the University of Cologne. The interfaces needed to process the road and public transport networks prepared by the working group IRPUD Dortmund were completed and tested and the classification of cars and commercial vehicles defined. The interfaces linking the modules calculating travel demand with the dynamic traffic assignment were defined. Alternative methods to model public transport route choice behaviour of travellers were compared and integrated into the existing multimodal route planner. The concept for modelling individual mobility was finalised and integrated into the existing dynamic assignment algorithm.

The module Psychological Actor Model of Individual Intentions and Decisions (PSI) is developed by the Institute of Theoretical Psychology of the University of Bamberg. The work has focused on the integration of the PSI-model into the weekly activity planner AVENA. The interfaces to link the activity model with the land use models and the AVENA activity planner are largely completed.

The module urban goods transport is developed by German Aerospace Center (DLR). The complexe work on modelling urban goods transport resulted in the decision to develop a simplified goods transport model in ILUMASS.

The module Microsimulation of environmental impacts of transport and land-use is developed by the Institute of Sustainable Infrastructure Planning of the University of Wuppertal (LUIS). The work on environmental impacts has focused on defining the main groups of moving and fixed emission sources and establishing the methodology of estimating emissions and spatial dispersion models of greenhouse gases, pollutants and traffic noise and defining the interfaces between the land-use and transport modules and the environmental sub-models.

\section{Integration and Module Structure in ILUMASS}

The ILUMASS project aims at integrating modules to a complete modelling system. The complete model ILUMASS consists of 6 sub-modules to characterise the complex interactions between urban development, general social-political conditions and mobility.

The first step involves the independent development of all sub-modules, and abstracts initially from the task of linking them with other models. The linkage of the modules and, in particular, the enabling of backward-linkages between the modules is a research topic that to date has received little analytical treatment.

The simulation procedure consists initially of processing a hierarchical chain of individual modules in a time interval. The output of the model then forms a subset of the input for the following model. A time interval is defined here by the longest typical simulation period of an individual module (e.g. for Dortmund this would be one year). The outputs of all the submodules serve in the next time interval as a new input data set. Such a system would be a bottom-up simulation were it not for the iterative backward linkages. In the ILUMASS model system there are both uni-dimensional cause-effect relationships as well as strongly linked 
connections between the activity reports of the surveyed individuals, the daily schedules, and the trip times in the network that are calculated by different sub-modules. Consistency between the data set thus necessitates consideration of the interactions between the modules. For example, following the calculation of concrete travel times over the network, the time that an individual has to conduct a certain activity during the day does not generally correspond to the original assumptions. The solution of this problem therefore requires an iterative approach.

For this purpose each individual module has to be integrated into a standardised operating system. In this step a visualisation of the modules is not realised, but the results of the simulation could be imported and processed in a conventional Geographic Information Systems. The data communication within the programme system will result via Input- and Output data files. The coordination of the programme system will be assumed by a control programme, which is currently under development by DLR.

The main tasks of this control programme are:

- successive running of the modules (programme parts)

- waiting for respective results before editing and running the next (further) module (programme steps) (see Figure 7).

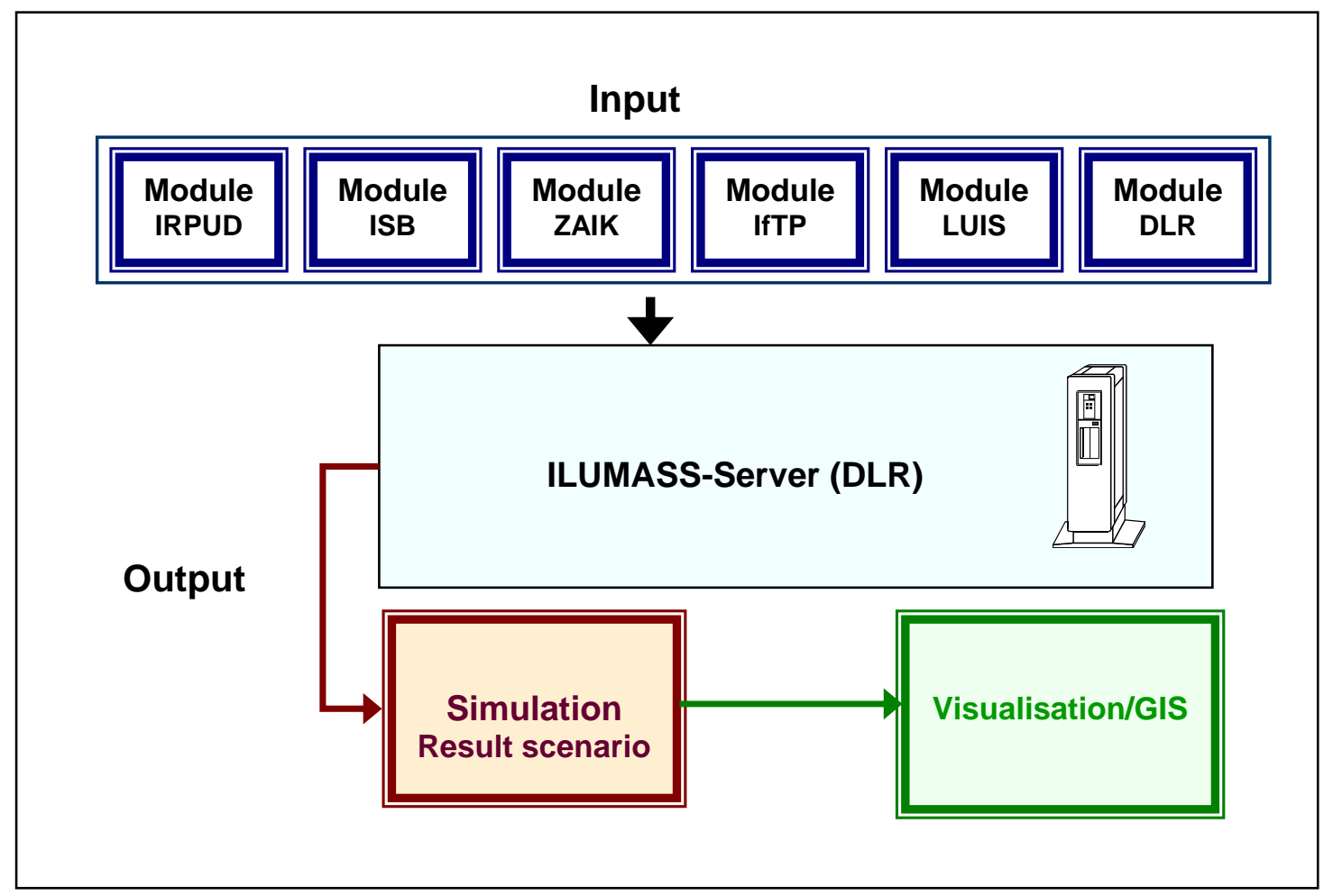

Figure 7. Integration and Module Structure in ILUMASS.

For this reason the new programme has the ability to run a complete scenario (simulation). Then the analysis of the several results will be carried out by each project member. With the adoption of data bases, the Module Integration is more flexible, however more complex. Therefore it is necessary to establish the data communication with data bases and not only via data files (Etches, 2000).

There are some advantages by using this approach. Potential Users (e.g. municipalities, planning bureaus) are able to adopt different scenarios direct from the data base with a comfortable (graphical) user interface. 


\section{Future Aspects of Land-Use/Transport/Environment Simulation Models}

The ILUMASS model is completely disaggregate and deals with micro locations and movements of individual agents and destinations (households, firms and persons) on a surface of pixel-like grid cells combining a microscopic land use model with a microscopic activity based travel demand model and microscopic environmental impact models in one unified modelling framework. It remains to be asked whether the movement towards ultimate disaggregation in content, space and time is the right way to go.

From a technical point of view, the prospects are excellent. More powerful computers will remove former barriers to increasing the spatial, temporal and substantive resolution of models. The wealth of publicly available high-resolution spatial data will reduce aggregation errors in spatial models. Geographic Information Systems will become the mainstream data organisation of urban models. Spatial disaggregation of land use and transport network data in raster GIS will permit the linkage between land use transport models and dispersion (emission-immission) air quality and noise propagation models. Multiple representation of spatial data in raster and vector GIS will combine the advantages of spatial disaggregation (raster) and efficient network algorithms (vector). It will be possible to replace aggregate probabilistic approaches (e.g. entropy maximising) by disaggregate stochastic (microsimulation) approaches.

When completed, the integrated ILUMASS model will be the only European counterpart to the growing number of large North-American modelling projects utilising advanced microsimulation approaches for the integrated planning of sustainable land use, transport and environment in urban regions, such as the California Urban Futures (CUF) Model at the University of California at Berkeley (Landis and Zhang, 1998a, 1998b), the Integrated Land Use, Transport and Environment (ILUTE) model at Canadian universities led by the University of Toronto (Miller, 2001), the Urban Simulation (UrbanSim) model at the University of Washington, Seattle (Waddell, 2000) and the models of the Transport and Land Use Model Integration Program (TLUMIP) of the Department of Transportation of the State of Oregon, USA. There are no efforts of comparable size in Europe. There are a few national projects, such as the Learning-Based Transportation Oriented Simultations System (ALBATROSS) of Dutch universities (Arentze and Timmermanns, 2000) or the ILUMASSProject in Germany described in this paper.

\section{Acknowledgements}

The joint research project ILUMASS is supported by a grant from the German Ministry of Education and Research (Bundesministerium für Bildung und Forschung - BMBF).

\section{References}

ALVANIDES, S., OPENSHAW, S., and MACGILL, J., 2001, Zone Design as a Spatial Analysis Tool, In TATE, N., and ATKINSON, P.M. (Eds), Modelling Scale in Geographical Information Science, London, 141-157.

ARENTZE, T., and TIMMERMANNS, H., 2000, ALBATROSS - A Learning Based Transportation Oriented Simulation System, European Institute of Retailing and Services Studies, Eindhoven.

CLARAMUNT, C., JIANG, B., and BARGIELA, A., 2000, A new framework for the 
integration, analysis and visualisation of urban traffic data within geographic information systems, In THILL, J.C. (Ed), Geographic Information Systems in Transportation Research, Oxford, 3-12.

DOHERTY, S.T., and MILLER, E.J., 2000, Interactive Methods for Activity Scheduling Processes, In GOULIAS, K. (Ed), Transportation, 27, (1), 75-97.

ETCHES, A., 2000, A Temporal Geo-Spatial Database in support of an Integrated Urban Transportation System, In ZAGEL, B. (Ed), GIS in Transport und Verkehr, Heidelberg, 33-44.

LANDIS, J., and ZHANG, M., 1998a, The second generation of the California urban futures model. Part 1: Model logic and theory, In Environment and Planning B: Planning and Design, Volume 25, 657-666.

LANDIS, J., and ZHANG, M., 1998b, The second generation of the California urban futures model. Part 2: Specification and calibration results of the land use change module, In Environment and Planning B: Planning and Design, Volume 25, 657-666.

MILLER, E.J., 2001, Integrated Land Use, Transportation, Environment (ILUTE) Modelling System, http://www.ilute.com/ (accessed 13 July 2003).

MOECKEL, R., SCHUERMANN, C., SPIEKERMANN, K., and WEGENER, M., 2003, Microsimulation of Land Use, In Proceedings of the 8th International Conference on Computers in Urban Planning and Urban Management (CUPUM), Sendai, Japan, Centre for Northeast Asian Studies (CD-ROM).

MOECKEL, R., SPIEKERMANN, K., and WEGENER, M., 2003, Creating a synthetic Population, In Proceedings of the 8th International Conference on Computers in Urban Planning and Urban Management (CUPUM), Sendai, Japan, Centre for Northeast Asian Studies (CD-ROM).

MÜHLHANS, H., and RINDSFÜSER, G., 2000, Computergestützte Erhebung und Analyse des Aktivitätsplanungsverhaltens, $S R L, \mathbf{6 8}$, Institut für Stadtbauwesen und Stadtverkehr, RWTH Aachen, 69-78.

RINDSFÜSER, G., MÜHLHANS, H., DOHERTY, S.T., and BECKMANN, K.J., 2003 (in press), Tracing the planning and execution of activities and their attributes - Design and application of a hand-held scheduling process survey, Paper presented at the $10^{\text {th }}$ International Conference on Travel Behaviour Research, August 10-15, 2003, Lucerne, Switzerland.

SCHÄFER, R.-P., STRAUCH, D., and KÜHNE, R., 2001, A Geographic Information System (GIS) for the Integration of Heterogenous Traffic Information, in GHASSEMI, F. (Ed), MODSIM 01.- Proceedings of the Conference MODSIM 01, Canberra/Australia, Dec. 2001, (Publications of The Australian National University, Canberra), 2075-2080.

SPIEKERMANN, K., and WEGENER, M., 2000, Freedom from the tyranny of zones: towards new GIS-based models, In FOTHERINGHAM, A.S., and WEGENER, M. (Eds), Spatial Models and GIS: New Potential and New Models, GISDATA 7, London, 45-61.

STRAUCH, D., HERTKORN, G., and WAGNER, P., 2002, Mikroskopische Verkehrssimulation, Flächennutzung und Mobilität - Entwicklung eines neuen Planungsinstrumentariums im Verbundprojekt ILUMASS, In MÖLTGEN, J., and WYTZISK, A. (Eds), GI-Technologien für Verkehr und Logistik, IfGI prints 13, Univ. Münster, Inst. f. Geoinformatik, Münster, 133-146.

THILL, J.-C., 2000, Geographic information systems for transportation in perspective, In THILL, J.-C. (Ed), Geographic Information Systems in Transportation Research, Oxford, 167-184. 
WADDELL, P, 2000, A behavioural simulation model for metropolitan policy analysis and planning: residential location and housing market components of Urban Sim, In Environment and Planning B: Planning and Design, Volume 27, 247-263.

WEGENER, M., 1998, Applied models of urban land use, transport and environment: stateof-the-art and future developments, In LUNDQVIST, L., MATTSON, L.-G., and KIM, T.J. (Eds), Network Infrastructure and the Urban Environment: Recent Advances in Land use/Transportation modelling, Berlin, Heidelberg, New York, 245267. 